\title{
Simulation and Design of Three-Level Cascaded Inverter Based on Soft Computing Method
}

\author{
Ayse Kocalmis BILHAN, Sedat SUNTER
}

\begin{abstract}
This paper presents the development and performance testing of the three-level inverter used in distributed power generation systems or Hybrid / Electric /Fuel Cell Vehicles, employing the Space Vector Pulse Width Modulation Technique (SVPWM). A separate isolated DC voltage source for the $\mathrm{H}$-bridge inverter structure can be considered as Fuel Cells (FCs), batteries, ultra-capacitors, photovoltaic (PV) panels or another alternative energy sources. The three-level SVPWM has been briefly presented with switching sequences and states using the proposed algorithm. Artificial Neutral Network (ANN) structure is applied to the system for detecting the sector in the space vector hexagon and then calculating the region in the sector sections. In this paper, a three-level cascaded inverter with passive load and active load using SVPWM technique has been modeled, simulated and performed for various operation conditions. This modulation strategy provides to get sinusoidal waveforms with less switching losses and with very low harmonic distortion at the output. Simulation and experimental waveforms of the three-level SVPWM inverter feeding R-L (passive) and induction motor (active) loads are presented and analyzed for various operating conditions to verify the model and proposed algorithm.
\end{abstract}

Keywords: artificial neural network; inverters; pulse width modulation; voltage control

\section{INTRODUCTION}

All researches show that people are addicted to the electricity and its components for almost all devices. However, in recent years, air pollution, global warming, forest destruction, limited fossil fuel sources and growing energy needs have drawn attention to clean and sustainable energy sources. Sun, wind, biomass, hydropower, hydrogen, etc. are some examples of such renewable energy sources $[1,2]$. The mechanical energy of water or wind can be converted into electricity, or biological wastes can be burned to produce heat. Solar energy is widespread and completely free of cost and it can generate electricity directly without environmental pollution, when exposed to solar radiation [3-5]. The solar energy can be converted into electrical energy by using silicon cells. Fuel Cells (FCs), which chemical energy converts into electrical energy, are basically called electrochemical device. Water and heat are the only co-products of the system [4]. Also FCs do not contain any moving parts, they have low losses and noise [6].

In the last decade, the increasing usage of the renewable energy sources (solar energy, fuel cell, wind energy, geothermal energy and etc.) brings some requirements such as power quality management or improving power supply reliability [7-9]. In addition, the improvements in power electronics and semiconductor technology have caused various changes and developments in power electronic systems such as multilevel (ML) based voltage-fed inverter circuits [10]. In the conventional twolevel inverter configurations, the switching losses limit the switching frequency for high power and voltage applications. However, this condition can be solved by increasing level numbers at the output voltage waveform of the inverter [11]. Minimum level number in multilevel inverters is detected as three. The three-level inverter generates five levels at line-to-line output voltages and it has fewer harmonic components than those of two-level inverter for the same switching frequency. Multilevel inverters have been mainly recommended for high- and medium-level power applications [12]. Multilevel inverters can be adopted in various applications in industry such as renewable energy systems or variable speed drive systems, etc. [13] because they can control the amplitude of the output voltage as well as frequency [14]. Multilevel inverters have many advantages compared to two level conventional inverters:

- ML inverters can generate voltage waveforms with high efficiency and low distortion at low switching frequencies,

- Large amount of voltages is easily shared between the series connected semiconductor devices [14, 15],

- The small common-mode (CM) voltages help to reduce stresses on the switch,

- Total Harmonic Distortion (THD) is reduced by increasing the level number, and when it reaches infinite, THD becomes zero [16].

Although many different multilevel inverter topologies have been proposed in literature, there are three well known topologies. These are; Cascaded H-Bridge ML Inverter [12], [17-19], Diode Clamped (Neutral Point Clamped NPC) ML Inverter [12], [20, 21] and FlyingCapacitor (FC) ML Inverter [12], [22, 23]. Each topology has its own advantages and disadvantages. The first approach to multilevel inverter is started with Cascaded HBridge ML Inverter. It is used to produce a staircase AC output by connecting separately DC source H-Bridges in series. However, it was not widely used until 1990s. In this study, a cascaded three-level inverter was taken into account, because the voltage sharing in the devices can be obtained by independent DC supplies and these DC voltage sources can be obtained from the renewable energy sources such as FCs, photovoltaic panels and etc. [24]. Since HBridge circuit structure is modular, this introduces an important advantage from the point of manufacturing and maintaining. In addition to these advantages, very high voltage inverters can be designed by using a number of $\mathrm{H}$ bridge inverters. Also this structure needs less electronic devices (clamped diodes and clamped capacitors) comparing to Neutral Point Clamped and Flying-Capacitor ML Inverters [25].

Pulse width modulation (PWM) techniques are used to obtain variable voltage and frequency supply and they are largely used in industrial and residential applications. 
Generation process of the PWM in ML inverters is more difficult than that in conventional two-level inverters. In the literature, many PWM techniques such as; Sinusoidal PWM (SPWM), third harmonic injection PWM (THIPWM), selective harmonic elimination PWM (SHEPWM), delta sigma PWM, Space Vector PWM, etc. have been studied for the purpose of control of the multilevel inverter systems. Among these, the Space Vector Pulse Width Modulation (SVPWM) technique is the most popular one [26-28]. The SVPWM technique is commonly used in three-level inverters as well as two-level inverter systems. The SVPWM algorithm has higher magnitude and better harmonic spectrum of the output voltage compared to SPWM. However, switches and their switching sequences are increased with the number of levels. Therefore, it is not easy to calculate the vector position and switching times for SVPWM ML inverter especially with high level numbers [27]. Due to the complex computation of the three-level SVPWM algorithm, it is preferable to implement it on softwarebased Digital Signal Processors (DSPs) or other microprocessors.

Recently, Artificial Neutral Network (ANN) has gained attention for complex applications and many ANN architectures have been developed. When the literature is examined, it can be seen that ANNs are used to solve many problems in different fields such as engineering, business and etc. [28-32]. Also ANNs are used for modeling, predicting, classification, control of complex systems, etc. In this study, vector position calculation has been realized by using a multi layer feed-forward neural network ANN. The network consists of three layers: input layer, hidden layer and output layer. Also the number of neurons in hidden layer will be determined by trial and error. Additionally, the proposed algorithm ensures that three adjacent vectors nearest to each other are easily selected. Also, the switching time of each voltage vector can be easily calculated for ML inverters.

Organization of the paper is as follow: Three phase three level cascaded inverter is reviewed in Section II. ANN based three level SVPWM technique is proposed in Section III. Simulation results are given in Section IV and experimental results are given in Section $\mathrm{V}$, too.

\section{THE THREE LEVEL CASCADED H-BRIDGE INVERTER}

Fig. 1 shows the power circuit of three-phase threelevel inverter feeding a load which can be inductive or passive load. The input supply of each $\mathrm{H}$-bridge inverter can be provided by FCs, batteries, ultra capacitors, photovoltaic panels (PV) [29] or etc. In this paper, the presented topology employs a single isolated DC source for each phase to generate three level output. The input voltage source and H-bridge have been modelled by using MATLAB/SimPowerSystem. The output voltage of the renewable energy source can be applied to an electrical machine through suitable $\mathrm{DC} / \mathrm{DC}+\mathrm{DC} / \mathrm{AC}$ converters or directly $\mathrm{DC} / \mathrm{AC}$ converter depending on the economical arrangement and power needs in the applications. However, in most cases, the output voltage of renewable energy sources is needed to be regulated. For this reason, an additional DC/DC converter (boost, buck or buck-boost converter) is used between renewable energy source and
$\mathrm{DC} / \mathrm{AC}$ inverter. In this work, DC source is taken as a constant value.

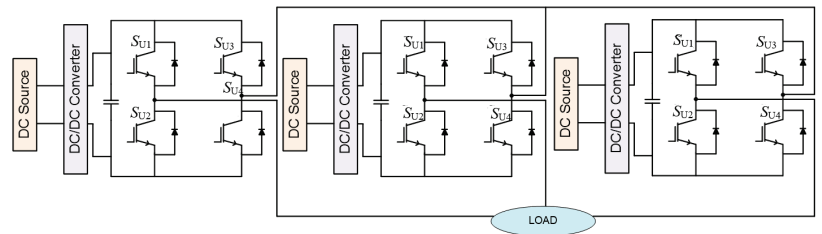

Figure 1 The model of three-phase three-level cascaded $\mathrm{H}$-bridge inverter

In each H-bridge inverter, various switching combinations of the switches used generate three-phase output voltage waveforms. $V_{\mathrm{DC}},-V_{\mathrm{DC}}$ and $0 \mathrm{~V}$ voltages are seen in the output phase voltage waveforms for three level inverters. If the switching state is ' 1 ' in one of the H-bridges (for instance the bridge supplying the output phase, $U$ ), it is indicated that $S_{\mathrm{U} 1}$ and $S_{\mathrm{U} 4}$ switches are on and therefore the inverter terminal voltage $V_{\mathrm{U}}$ with respect to the neutral point $N$ will be $+V_{\mathrm{DC}}$, whereas ' -1 ' denotes that the switches, $S_{\mathrm{U} 2}$ and $S_{\mathrm{U} 3}$ are both on. In this case, $V_{\mathrm{U}}$ will be

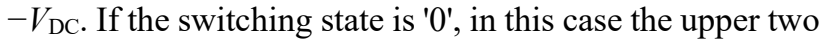
switches, $S_{\mathrm{U} 1}$ and $S_{\mathrm{U} 3}$ or lower two switches, $S_{\mathrm{U} 2}$ and $S_{\mathrm{U} 4}$ depending on the direction of the load current, $I_{\mathrm{A}}$ will be on and therefore the output voltage will be zero [11].

In SVPWM technique, the position of vector $V^{*}$ is specified using the phase angle of the three-phase system. For any kind of inverter; $\boldsymbol{V}^{*}$ and the phase angle, $\theta$ can be calculated as;

$$
\begin{aligned}
& V_{\mathrm{U}}=V_{m} \sin (\omega t) \\
& V_{\mathrm{V}}=V_{\mathrm{m}} \sin \left(\omega t-\frac{2}{3} \pi\right) \\
& V_{\mathrm{W}}=V_{\mathrm{m}} \sin \left(\omega t+\frac{2}{3} \pi\right) \\
& \boldsymbol{V}^{*}=V_{\mathrm{ref}}=V_{\mathrm{d}}+j \cdot V_{\mathrm{q}} \frac{2}{3}\left(V_{\mathrm{U}}+V_{\mathrm{V}} \mathrm{e}^{j \frac{2 \pi}{3}}+V_{\mathrm{w}} \mathrm{e}^{-j \frac{2 \pi}{3}}\right) \\
& \theta=\tan \left(\frac{V_{\mathrm{q}}}{V_{\mathrm{d}}}\right)^{-1}
\end{aligned}
$$

\section{CONVENTIONAL SECTOR AND REGION DETERMINATION}

All three phase n-level inverters consist of six sectors and each sector is divided into $(n-1)^{2}$ triangles [30]. The switching states are calculated as $n^{3}$. As shown in Fig. 2, a three-level inverter is defined by $3^{3}$ switching states (28). According to this knowledge, the three-level inverter has six sectors named as Sector A, Sector B, Sector C, Sector $\mathrm{D}$, Sector $\mathrm{E}$ and Sector $\mathrm{F}$ in the space vector diagram, it is indicated in Fig. 2. Also each sector consists of four regions $(1,2,3,4)$. The three-level inverter includes 24 active states and 3 zero states in the space vector diagram. Furthermore, the active vectors can be separated into three groups as small voltage vectors $\left(\boldsymbol{V}_{\mathbf{1}}, \boldsymbol{V}_{\mathbf{2}}, \ldots, \boldsymbol{V}_{\mathbf{6}}\right)$, medium voltage vectors $\left(\boldsymbol{V}_{\mathbf{7}}, \boldsymbol{V}_{\mathbf{8}}, \ldots, \boldsymbol{V}_{\mathbf{1 2}}\right)$ and large voltage vectors $\left(V_{13}, V_{14}, \ldots, V_{18}\right)$. The zero vectors $\left(V_{0}\right)$ are pointed at the origin of the hexagon. There are only three possible configurations for zero vectors, two possible 
configurations for each of the small vectors and one possible configuration for each middle or large vectors.

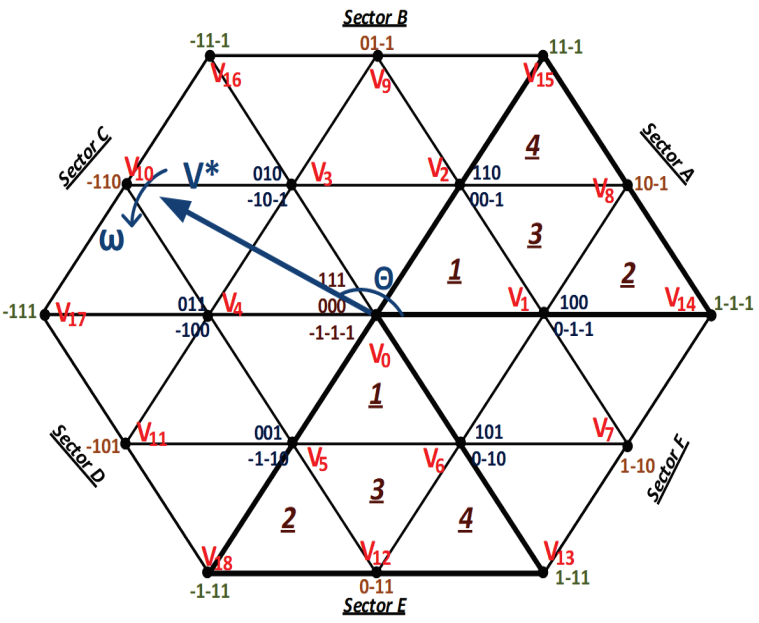

Figure 2 Sectors, regions and vectors of three-level space vector PWM

Based on the SVPWM algorithm, the command voltage vector $\left(V^{*}\right)$ is synthesized by using a combination of three adjacent vectors. These vectors could consist of two adjacent active and one or both zero vectors or all of the vectors could be three adjacent active switching vectors. Each voltage vector has its own dwelling times and they are calculated by using vector calculation equations [18];

$T_{\mathrm{U}} \cdot V_{\mathrm{U}}+T_{\mathrm{V}} \cdot V_{\mathrm{V}}+T_{\mathrm{W}} \cdot V_{\mathrm{W}}=T_{\mathrm{S}} \cdot V^{*}$

$T_{\mathrm{U}}+T_{\mathrm{V}}+T_{\mathrm{W}}=T_{\mathrm{S}}$

where $V_{\mathrm{U}}, V_{\mathrm{V}}$, and $V_{\mathrm{W}}$ are voltage vectors. They are used to define the triangle location of $\boldsymbol{V}^{*}$ voltage vector. $T_{\mathrm{S}}$ is the sampling time and $T_{\mathrm{U}}, T_{\mathrm{V}}$ and $T_{\mathrm{W}}$ are the corresponding vector times. The position of the command voltage $\left(V^{*}\right)$ can be easily calculated by using simple algorithm such as the conventional two-level inverter topology. Unfortunately, the complexity of algorithm increases as the inverter level increases [18].

The following procedure shows SVPWM steps for more than three-level applications $[10,11,22]$ :

a) Determination of amplitude $\left(\boldsymbol{V}^{*}\right)$ and angle $(\theta)$ of command voltage vector.

Value of $\boldsymbol{V}^{*}$ and $\theta$ is calculated by using Eq. (1), Eq. (2) and Eq. (3).

b) Sector and region identification.

In the conventional three-level SVPWM, sector is defined by using value of $\theta$ and region is defined by using value of $\boldsymbol{V}^{*}$.

If $\theta$ is between $0^{\circ} \leq \alpha<60^{\circ}$, then $V^{*}$ is in Sector A, If $\theta$ is between $60^{\circ} \leq \alpha<120^{\circ}$, then $V^{*}$ is in Sector B, If $\theta$ is between $120^{\circ} \leq \alpha<180^{\circ}$, then $V^{*}$ is in Sector C, If $\theta$ is between $180^{\circ} \leq \alpha<240^{\circ}$, then $\boldsymbol{V}^{*}$ is in Sector D, If $\theta$ is between $240^{\circ} \leq \alpha<300^{\circ}$, then $\boldsymbol{V}^{*}$ is in Sector E, If $\theta$ is between $300^{\circ} \leq \alpha<360^{\circ}$, then $\boldsymbol{V}^{*}$ is in Sector F, In order to determine the region, $\boldsymbol{V}^{*}$ is used to calculate the modulation index, $m$, as in Eq. (6).

$m=\sqrt{3} \frac{\boldsymbol{V}^{*}}{V_{\mathrm{DC}}}$
In the conventional three-level inverter, $\mathrm{m}$ is used to calculate $m_{1}$ and $m_{2}$ by using $\theta[10]$. As it is seen from Fig. 3 , Sector $\mathrm{C}$ is divided into 4 regions and $m_{1} / m_{2}$ have been calculated by using Eq. (7) for sector C.

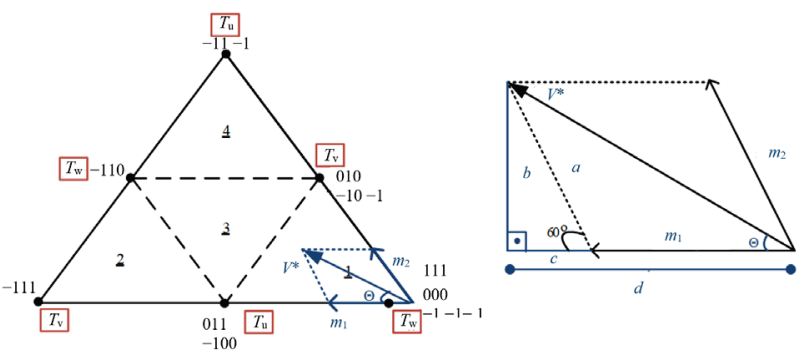

Figure 3 Space vector diagram for Sector C, $m_{1}$ and $m_{2}$

$$
\left.\begin{array}{l}
m_{1}=2 m \frac{\sin (\pi-\theta)}{\sqrt{3}} \\
m_{2}=m \frac{\cos (\pi-\theta)-\sin (\pi-\theta)}{\sqrt{3}}
\end{array}\right\}
$$

And then, the position of the voltage vector $V^{*}$ is stated by using values of $m_{1}$ and $m_{2}$. This process has to be done for all Sectors and Regions.

\section{ANN BASED SECTOR AND REGION DETERMINATION}

In the literature, many types of ANN architecture are available. ANNs are becoming useful as an alternative way to conventional methods. A different modeling approach to solve complicated problems is presented by ANNs. In this paper, the position of the reference vector $\left(V^{*}\right)$ is determined by using ANN. The back-propagation training algorithm is used for minimization of a cost function of the error between the outputs and the input of the feed forward ANN. The performance of the ANN depends on the functions used by the hidden layer and how the neural network has been trained. In this work, ANN structure is used for the sector and region determination. Each ANN has five layer structures as one input layer, three hidden layers and one output layer. Fig. 4 illustrates the diagram of the ANN used in this study.

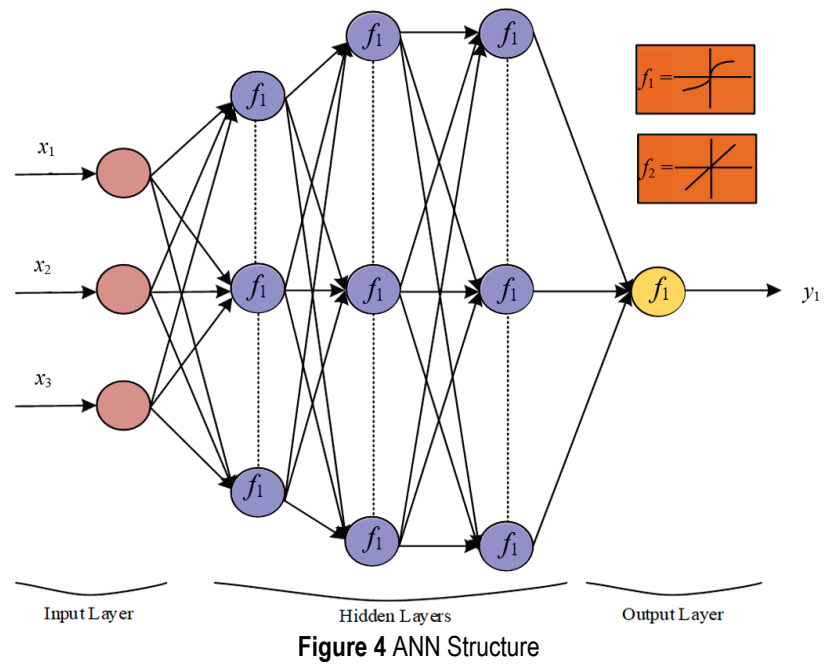

Input layer consists of the vector angle $(\theta)$ as $x_{1}$, modulation index $(m)$ as $x_{2}$ and output frequency $(f)$ as $x_{3}$. 
The tan-sigmoid activation function is used for all three hidden layers. The numbers of each neuron for hidden layers are 7,15 and 15, respectively. The linear activation function is used for output layer. The LevenbergMarquardt learning algorithm is applied to achieve optimum ANN for 100 epochs and reached an error below $0,00001 \%$. The performance evaluations $(P E)$ of the networks are performed by Eq. (8) where $e$ is an error:

$$
P E=\frac{1}{2} e^{2}
$$

Tab. 1 gives the switching times, $T_{\mathrm{U}}, T_{\mathrm{V}}$ and $T_{\mathrm{W}}$ defined for Sector C.

Table 1 Vector durations for Sector $\mathrm{C}$

\begin{tabular}{|c|c|c|c|c|c|}
\hline & & $1^{\mathrm{ST}}$ Region & $2^{\mathrm{ND}}$ Region & $3^{\mathrm{RD}}$ Region & $4^{\mathrm{TH}}$ Region \\
\hline \multirow{4}{*}{$\mathrm{C}$} & $T_{\mathrm{U}}$ & $T_{\mathrm{S}} \cdot m \cdot \sin \theta$ & $T_{\mathrm{S}}(1-(m \cdot \sin (\theta-\pi / 3))$ & $T_{\mathrm{S}} / 2(1+2 m \cdot \sin (\theta+\pi / 3))$ & $-T_{\mathrm{S}} / 2(1+2 m \cdot \sin (\theta+\pi / 3))$ \\
\cline { 2 - 6 } & $T_{\mathrm{V}}$ & $T_{\mathrm{S}} / 2(1-2 m \cdot \sin (\theta-\pi / 3))$ & $-T_{\mathrm{S}} \cdot m \cdot \sin (\theta+\pi / 3)$ & $T_{\mathrm{S}} / 2(2 m \cdot \sin (\theta-\pi / 3)-1)$ & $T_{\mathrm{S}} \cdot m \cdot \sin \theta$ \\
\cline { 2 - 6 } & $T_{\mathrm{W}}$ & $-T_{\mathrm{S}} \cdot m \cdot \sin (\theta+\pi / 3)$ & $T_{\mathrm{S}} / 2(2 m \cdot \sin (\theta-\pi / 3)-1)$ & $T_{\mathrm{S}} / 2(1-2 m \cdot \sin \theta)$ & $T_{\mathrm{S}}(1-(m \cdot \sin (\theta-\pi / 3))$ \\
\hline
\end{tabular}

\section{SELECTION OF SWITCHING SEQUENCES AND CORRESPONDING STATES}

The switching sequences have to be selected after the switching times are calculated. As can be seen from Fig. 2, each sector has a different number of state. It is important to notice that only one device has to change its state at any time when the switching sequences are selected. Hence, minimum switching loss and minimum total harmonic distortion (THD) can be achieved. In this work, all appropriate switching states are organized to generate switching sequences to obtain low THD. Tab. 2 gives a list of the switching sequences in the regions for Sector $\mathrm{C}$.

Table 2 Switching Sequences for Three-Level SVPWM in Sector C

\begin{tabular}{|c|c|c|}
\hline \multirow{4}{*}{ Sector C } & $1^{\mathrm{ST}}$ Region & $2^{\mathrm{ND}}$ Region \\
\cline { 2 - 3 } & $-1-1-1,-10-1,-100,000$, & $-10-1,-11-1-110$, \\
& $010,011,111$ & 010 \\
\cline { 2 - 3 } & $3^{\mathrm{RD}}$ Region & $4^{\mathrm{TH}}$ Region \\
\cline { 2 - 3 } & $-10-1,-100,-110,010,011$ & $-100,-110,-111,011$ \\
\hline
\end{tabular}

\section{SIMULATION MODEL FOR ANN BASED THREE-LEVEL INVERTER WITH SPACE VECTOR PWM}

Fig. 5 shows MATLAB Simulink model of the system. The MATLAB / SimPowerSystem package program is used for modeling and simulating the whole system. Threephase sinusoidal modulation waves, $V_{\mathrm{U}}, V_{\mathrm{V}}$ and $V_{\mathrm{W}}$ are transformed into $V_{\text {alpha }}$ and $V_{\text {beta }}$ in "U-V-W / Alpha-Beta" block using Clarke transformation equations. $V_{\text {ref }}$ and angle $(\theta)$ of the reference voltage vector is calculated in

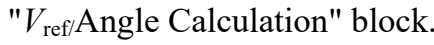

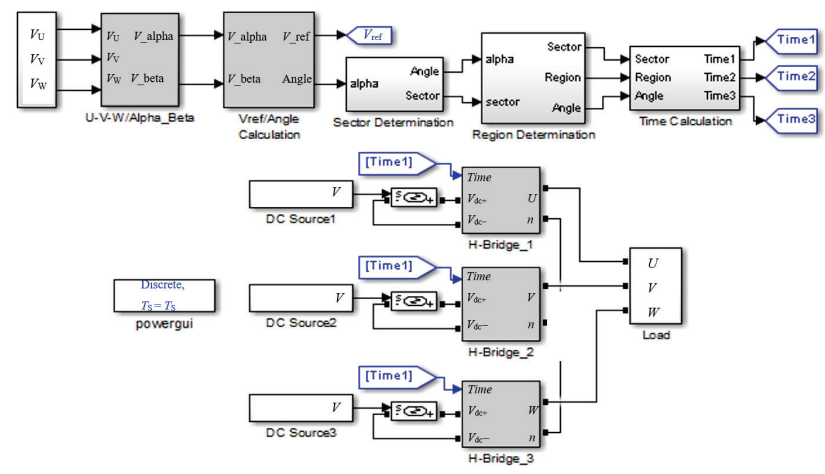

Figure 5 MATLAB/SimPowerSystem block of the whole system

Then, sector and region calculations are performed by "Sector Determination" and "Region Determination" blocks using ANN algorithm. Finally, in the "Time Calculation" block, switching times and sequences of the switches (totally 12) located in the cascaded H-bridge inverter are calculated and then applied to the switches in each of H-bridge blocks by "Times" function.

Isolated DC input supplies for the three-level inverter are obtained by using "DC sources". If the output voltage is obtained by using one of the renewable energy sources, the DC voltage is needed to be regulated by using DC/DC converter before applying to each H-Bridge structure.

\section{EXPERIMENTAL SETUP}

Fig. 6 shows the block diagram of the proposed ANN based three-level inverter with SVPWM algorithm including the induction motor load. "DSP" controller block determines the sector (Sector A, Sector B, ..., Sector F) and region $(1,2,3,4)$ in SVPWM by using artificial neural network. In addition, this block is used to calculate the switching times. Three-phase currents, phase and line voltages and machine speed are input to this block and the speed control is performed inside the block. "M57140" is a power supply which consists of an isolated DC/DC converter used for Intelligent Power Module (IPM) module. "Optocoupler/Dead Time" block provides electrical isolation and introduces a dead time between the switching signals. "Protection Circuit" block protects the IPM.

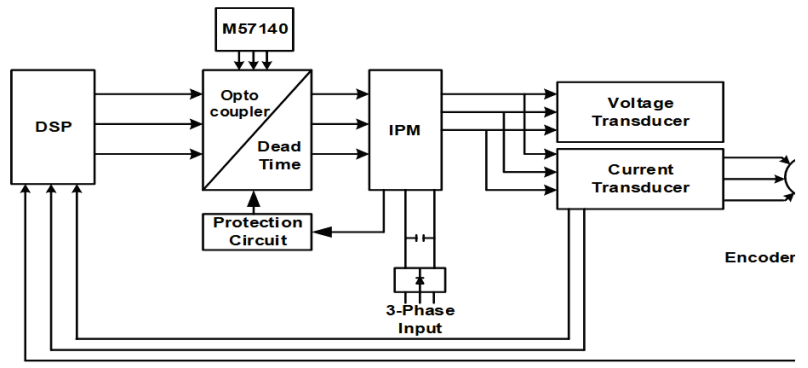

Figure 6 Block diagram of the proposed system

M57140 module has four isolated DC voltage outputs as $15 \mathrm{~V}$ with two different output current ratings $(30 \mathrm{~mA}$ and $100 \mathrm{~mA}$ ). The single M57140 module is used for each phase. These modules provide necessary voltage and current for input of each IPM. "IPM" block represents the three-level inverter power circuit. In this study, PM30CSJ060 type IPM was used. Three controller cards, one for each phase, were designed for IPMs. "Voltage 
Transducer" and "Current Transducer" blocks are used to measure the output voltages and currents, respectively. The induction motor parameters are given in Appendix.

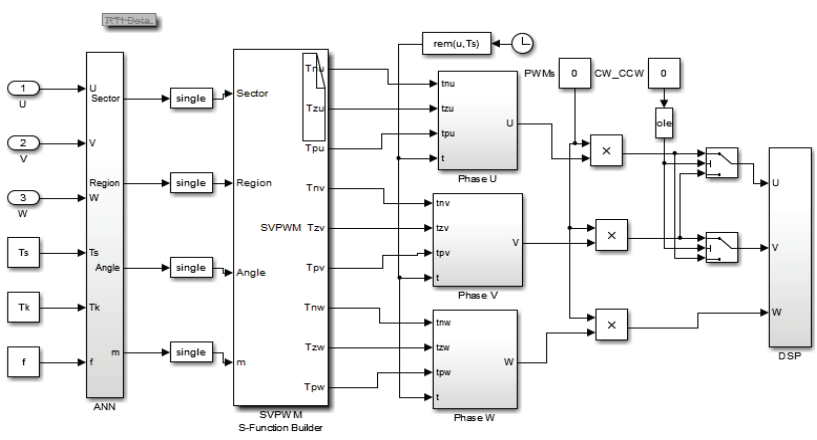

Figure 7 MATLAB/SimPowerSystem experimental block of the whole system

Fig. 7 illustrates MATLAB / SimPowerSystem model of the complete system. The model includes modulation index, sector and region determination, switching time calculations for all sectors and timing patterns blocks as well.

"ANN" block calculates the angle $(\theta)$ and the position of $\boldsymbol{V}^{*}\left(V_{\text {ref }}\right)$ which lies in the sector and region. The threephase sinusoidal modulation waves, switching time, simulation time and output frequency are used to calculate $\boldsymbol{V}^{*}$ and $\theta$. The switching sequences and duty cycles of the switches are calculated in "SVPWM" block. In the "U", "V" and "W" blocks, switching sequences are applied consequently. "DSP" block represents a real processor. All switching signals applied to the power devices are generated by this block.

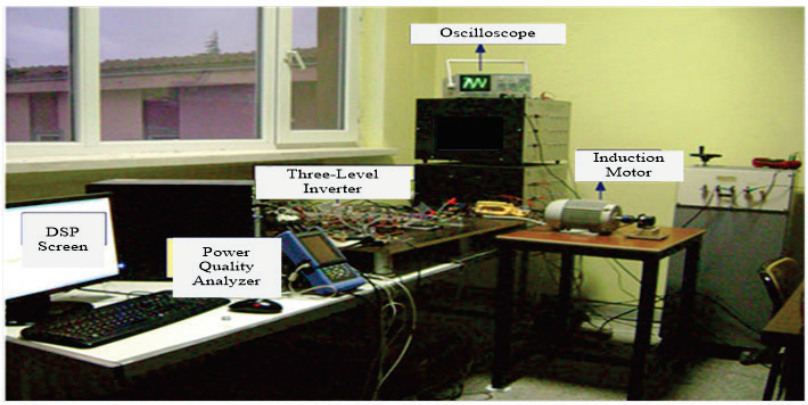

(a)

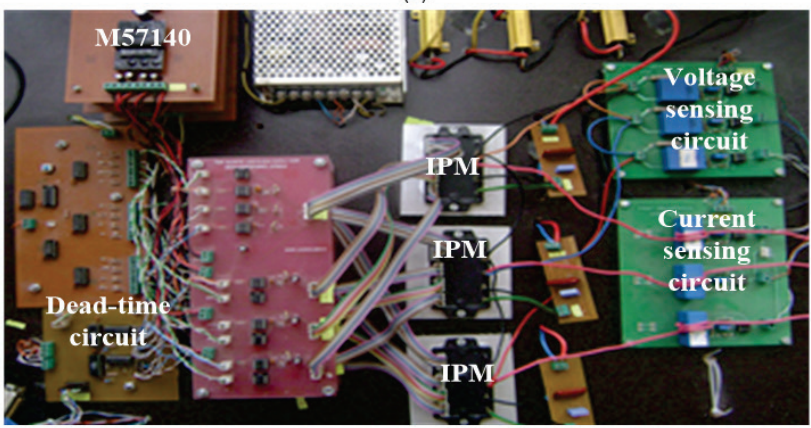

(b)

Figure 8 Photographs from the drive system

Fig. 8 shows the experimental setup. A photograph taken from the drive system given in Fig. 8(a). Fig. 8(b) shows the close view of the circuits. The proposed SVPWM algorithm has been implemented on a three-level cascaded H-bridge inverter feeding both $R L$ load and a 1,5 $\mathrm{kW}$ three-phase induction motor at no-load. The values of
$R$ and $L$ were taken $100 \Omega$ and $0,1 \mathrm{H}$, respectively. The drive system is tested at various operating conditions with open-loop $V / f$ control. The carrier frequency chosen for PWM generation is $1 \mathrm{kHz}$ and DC link voltage source taken which represents the solar panel is $47 \mathrm{~V}$. The death time introduced between the switches is $3,7 \mu \mathrm{s}$. The proposed three-level SVPWM algorithm is implemented by using DSP-1104 controller. HIOKI 3197 and Lecroy oscilloscope are used to measure output voltage, output current and FFT of the voltage and current. PM30CSJ060 IPM module has been used for each phase. The module is suitable for power switching applications. The module consists of six IGBT switches arranged as three-phase inverter. In the experimental setup, only two legs (singlephase) have been used as H-bridge. The other output is left as spare to replace the broken leg in case of a fault. The output current and voltage ratings of PM30CSJ060 module are $30 \mathrm{~A}$ and $600 \mathrm{~V}$, respectively.

\section{SIMULATION AND EXPERIMENTAL RESULTS}

Simulation and experimental results were obtained for various operating conditions. Simulation and corresponding experimental results for the output line voltage, load currents and their FFT are given in Fig. 9 Fig. 11 for $R L$ load. Similar results in Fig. 12 - Fig. 18 are also taken for induction motor load. First, the performance of the three-level SVPWM inverter is analyzed at low output frequency and low output voltage values. The results given in Fig. 9 are taken for $10 \mathrm{~Hz}$ output frequency and modulation index of 0,2. Fig. 9 illustrates simulation and experimental results of the output line voltage and load current, harmonic spectra of the line voltage and current waveforms.
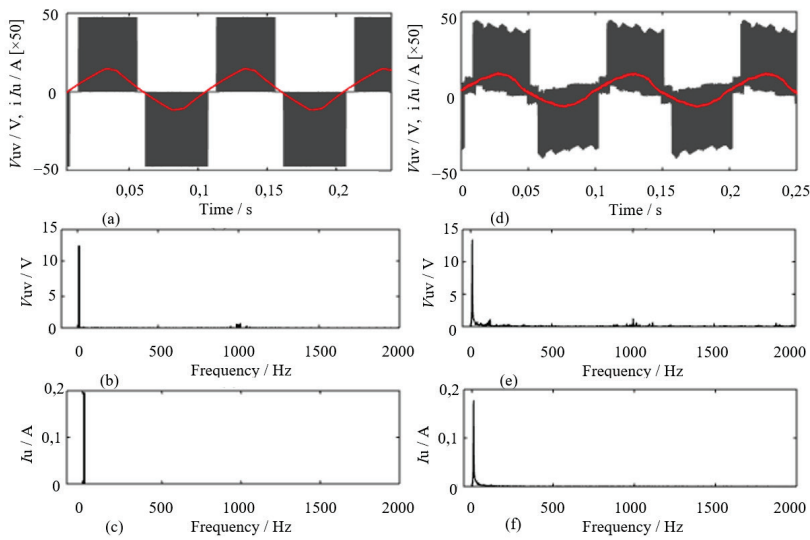

Figure 9 Simulation results $\left(m=0,2 ; f_{0}=10 \mathrm{~Hz}\right.$ ) (a) Output line voltage and current, (b) FFT of voltage waveform, (c) FFT of load current waveform, Experimental results $\left(m=0,2 ; f_{0}=10 \mathrm{~Hz}\right)$ (d) Output line voltage and current,

(e) FFT of voltage waveform, (f) FFT of load current waveform

As can be seen from Fig. 9(a) and Fig. 9(d), output line voltage waveforms obtained from simulation and experimental setup have only three levels since the modulation index $(m)$ has a low value as 0,2 . In this case, the reference voltage vector is located in Region 1 for all sectors as mentioned in Section III.

Simulation and experimental results have been repeated for $10 \mathrm{~Hz}$ output frequency and $m=0,8$ modulation index and results are given in Fig. 10. where the only distinct difference from the previous results is that 
the output line voltage has five levels instead of three as expected since the $\mathrm{m}$ has been increased to 0,8 .
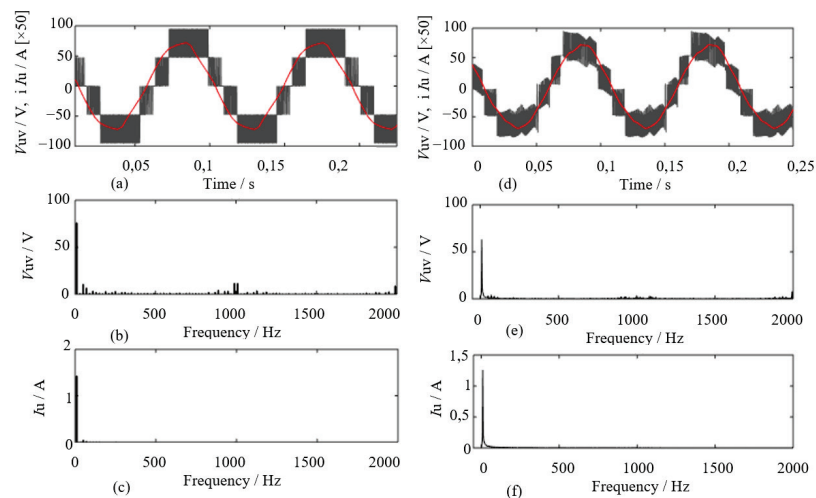

Figure 10 The Simulation results ( $m=0,8, f_{0}=10 \mathrm{~Hz}$ ) (a) Output line voltage and current, (b) FFT of voltage waveform, (c) FFT of load current waveform. Experimental results $\left(m=0,8, f_{0}=10 \mathrm{~Hz}\right.$ ) (d) Output line voltage and current,

(e) FFT of voltage waveform, (f) FFT of load current waveform

Similar results were taken for output frequency of 70 Hz. Simulation and experimental voltage and current waveforms and their corresponding spectra are shown in Fig. 11 for $m$ of 0,8 .

As is seen from Fig. 11, the voltage level will increase to five level within modulation index $(m=0,8)$.
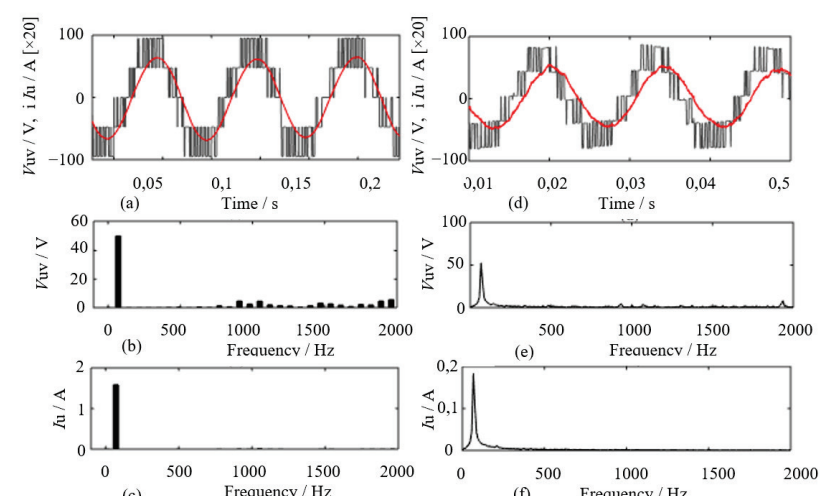

Figure 11 Simulation results $\left(m=0,8 ; f_{0}=70 \mathrm{~Hz}\right.$ ) (a) Output line voltage and current, (b) FFT of voltage waveform, (c) FFT of load current waveform. Experimental results $\left(m=0,8 ; f_{0}=10 \mathrm{~Hz}\right)$ (d) Output line voltage and current,

(e) FFT of voltage waveform, (f) FFT of load current waveform

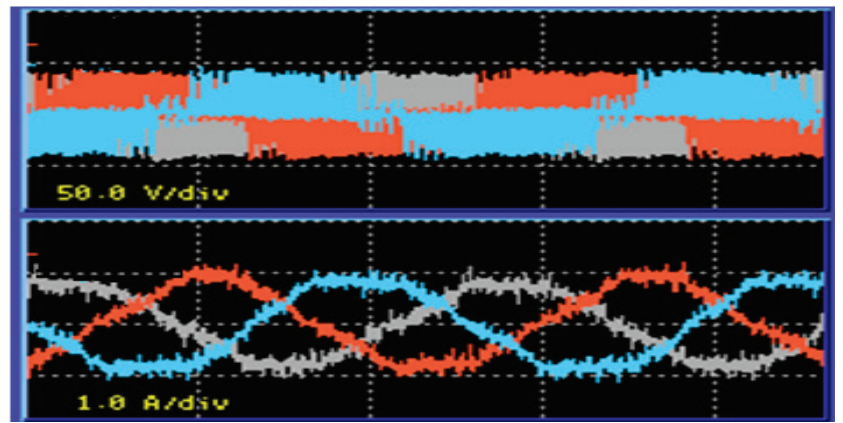

Figure 12 Three-phase output line voltages and motor currents $(f=10 \mathrm{~Hz})$

The experimental results shown in Fig. 13 - Fig. 16 were taken for an induction motor load. The three-phase motor currents shown in Fig. 13 have sinusoidal shapes even though the switching frequency is as low as $1 \mathrm{kHz}$. The line voltage waveform and its harmonic spectrum are given in Fig. 14. Here, the output voltage waveform has only harmonics around the switching frequency $(1 \mathrm{kHz})$ in addition to the main harmonic. Fig. 15 shows the motor speed variations for various speed reference conditions on no load. In this case, the motor speed is accelerated from standstill to $300 \mathrm{rpm}$ and stays in steady-state for a while. Then, the reference is changed to $-300 \mathrm{rpm}$. In Fig. 16, the motor current at the speed transition (from $300 \mathrm{rpm}$ to -300 $\mathrm{rpm}$ ) has been shown in detail. It should be noted that no control action has been taken here.
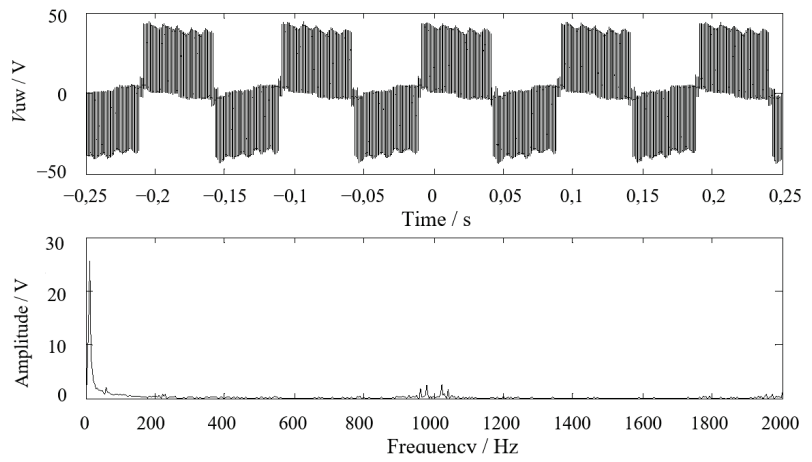

Figure 13 Output line voltage and its harmonic spectrum $(f=10 \mathrm{~Hz})$

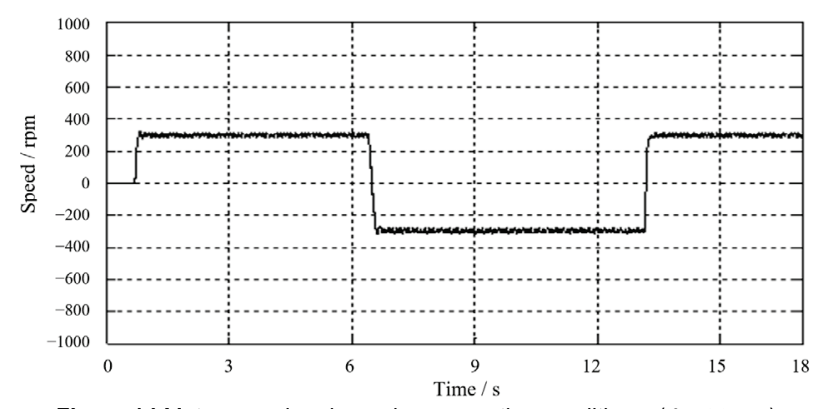

Figure 14 Motor speed under various operating conditions. $(f=10 \mathrm{~Hz})$

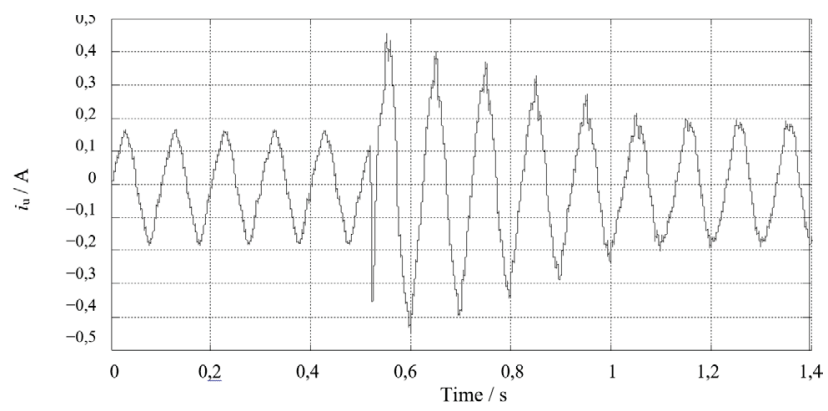

Figure 15 Motor current during speed reversal

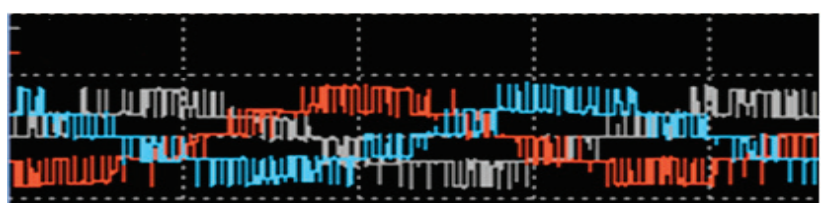

180.0 V/div

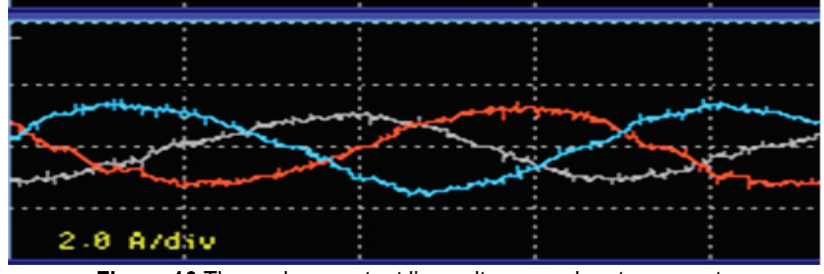

Figure 16 Three-phase output line voltages and motor currents

Similar experimental results for the induction motor load were realized for the output frequency of $30 \mathrm{~Hz}$ and the results are shown in Fig. 17, Fig. 18 and Fig. 19. The 
modulation index has been increased to maintain constant V/f operation. This can be easily seen from Fig. 17 where the output line voltage waveform has five levels.
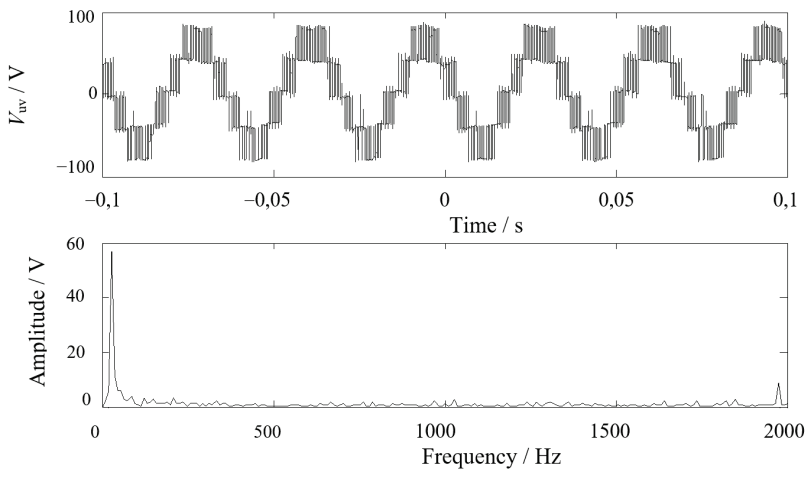

Figure 17 Line-to-line output voltage and its harmonic spectrum

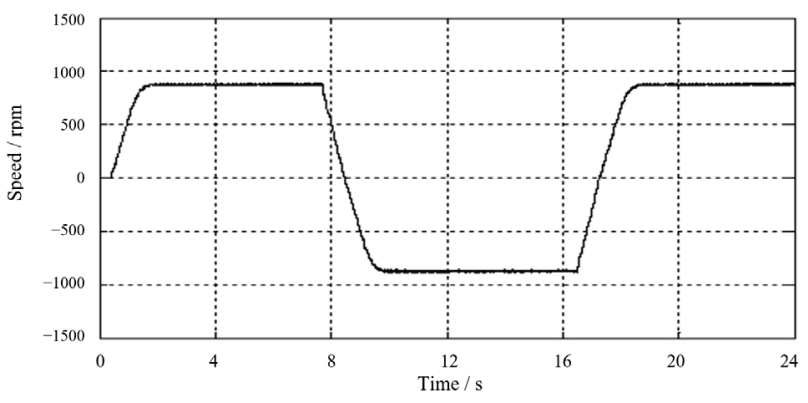

Figure 18 Motor speed under various operating conditions

\section{CONCLUSION}

The environmental concerns and the progressive decrease of the fossil fuels force governments and researchers to find other energy sources such as solar, wind or FCs. The new alternative energy sources will not be used only for heating and electricity power, they will be also used for propulsion motor of the vehicles. And in the near future, renewable energy sources will have common usage all around the world. This paper offers an alternative approach for usage of multilevel inverter for residential and vehicle applications. This work aims to help to improve system architecture and productivity.

In this work, the cascaded H-bridge multilevel inverter feeding an induction motor has been modelled and designed. SVPWM technique was used to control the switches in cascaded multilevel inverter. The proposed control algorithm offers less switching losses since only one device changes its state at each sampling time. Because each $\mathrm{H}$-bridge inverter configuration requires a separate isolated DC source, the cascaded H-bridge multilevel inverter structure is very convenient for any kind of renewable energy sources. Therefore, the proposed drive system can be easily adapted to the renewable energy systems.

A feedforward neural network based ANN is used to determine the vector location (sector and region) for SVPWM technique. The back propagation learning algorithm is used for training. The sectors and regions were calculated by using ANN architecture. The calculation complexity of the sectors and the regions for the SVPWM algorithm especially at high level numbers in multilevel inverters is decreased with the proposed algorithm comparing to the classical algorithms.

The simulation and experimental results were presented comparatively for various operating conditions. FFT analysis of the output voltage waveform shows that there are only harmonics around the switching frequency. This modulation strategy provides to get sinusoidal waveforms with less switching losses and with very low harmonic distortion at the output.

\section{APPENDIX}

Ratings of the three-phase, 4-pole, $380 \mathrm{~V}, 50 \mathrm{~Hz}$ squirrel cage induction motor are:

$P_{\mathrm{N}}=0,55 \mathrm{KW}, V=380 \mathrm{~V}, f=50 \mathrm{~Hz}, R_{\mathrm{s}}=112,4 \Omega, L_{\mathrm{s}}$ $=85,04 \mathrm{mH}, R_{\mathrm{r}}=110 \Omega, L_{\mathrm{r}}=85,01 \mathrm{mH}, L_{\mathrm{m}}=0,4 \mathrm{H}, J=$ $0,00131 \mathrm{kgm}^{2}, P=4$.

\section{Acknowledgements}

The authors are grateful to the TUBITAK for the support of this work through the project 108E151.

\section{REFERENCES}

[1] Tsai, H. L., Tu, C. S., \& Su, Y. J. (2008). Development of Generalized Photovoltaic Model Using MATLAB/ SIMULINK. Proceedings of the World Congress on Engineering and Computer Science, San Francisco, USA, 846-851.

[2] Tolbert, L. M., Peng, F. Z., \& Habetler, T. G. (1999). Multilevel converters for large electric drive. IEEE Trans. on Industry Applications, 35(1), 36-44. https://doi.org/10.1109/28.740843

[3] Seyezhai, R. \& Mathur, B. L. (2011). Modeling and control of a PEM fuel cell based hybrid multilevel inverter. International Journal of Hydrogen Energy, 36(22), 1502915043. https://doi.org/10.1016/j.jijhydene.2011.04.019

[4] Nehrir, M. H. \& Wang, C. (2009). Modeling and Control of Fuel Cells. Wiley, IEEE Pres. https://doi.org/10.1109/9780470443569

[5] Larminie, J. \& Dicks, A. (2003). Fuel cell systems explained. (2nd ed.)Wiley, Chichester and Hoboken, NJ. https://doi.org/10.1002/9781118878330

[6] Carrasco, J. M., et al. (2006). Power-Electronic Systems for the Grid Integration of Renewable Energy Sources: A Survey. IEEE Trans. on Industrial Electronics, 53(4), 1021016. https://doi.org/10.1109/TIE.2006.878356

[7] Bose, B. K. (2001). Modern power electronics and $A C$ drives. Prentice Hall, NJ, USA.

[8] Kocalmis, A. \& Sunter, S. (2006). Simulation of a space vector pwm controller for a three-level voltage-fed inverter motor drive. IEEE Industrial Electronics Society (IECON'06), 1915-1920, Paris. https://doi.org/10.1109/IECON.2006.347442

[9] Mondal, S. K., Bose, B. K., Oleschuk, V., \& Pinto, J. O. P. (2003). Space vector pulse width modulation of three-level inverter extending operation into overmodulation region. IEEE Trans. on Power Electronics, 18(2), 604-611. https://doi.org/10.1109/TPEL.2003.809342

[10] Lee, D. M., Jung, J. W., \& Kwak, S. S. (2011). Simple space vector pwm scheme for 3-level npc inverters including the overmodulation region. Journal of Power Electronics, 11(5), 688-695. https://doi.org/10.6113/JPE.2011.11.5.688

[11] Celanovic, N. \& Boroyevich, D. (2001). A fast space-vector modulation algorithm for multilevel three-phase converters. IEEE Trans. on Industry Applications, 37(2), 637-641. 
https://doi.org/10.1109/28.913731

[12] Somasekhar, T. \& Gopakumar, K. (2003). Three-level inverter configuration cascading two two-level inverters. Proc. Inst. Elect. Eng.Electr. Power Appl., 150(3), 245-254. https://doi.org/10.1049/ip-epa:20030259

[13] Kocalmis Bilhan, A. (2012). Design of the space vetor pwm controlled the cascaded three level inverter using soft computing techniques. Phd. Thesis.

[14] Wu, B. (2006). High-power converters and ac drives. IEEE Press, Hoboken, New Jersey. https://doi.org/10.1002/0471773719

[15] Lai, J. \& Peng, F. (1996). Multilevel converters-A new breed of power converters. IEEE Trans. Industrial Electronics, 32, 509-517. https://doi.org/10.1109/28.502161

[16] McGrath, B. P. \& Holmes, D. G. (2002). Multicarrier PWM strategies for multilevel inverters. IEEE Trans. Industrial Electronics, 49(4), 858-867. https://doi.org/10.1109/TIE.2002.801073

[17] Lee, S. G., Kang, D. W., Lee, Y. H., \& Hyun, D. S. (2001). The carrier-based PWM method for voltage balance of flying capacitor multilevel inverter. Conf. Rec. IEEE-PESC, 126131, Canada Vancouver.

[18] Priyan, S. \& Ramani, K. (2013). Implementation of closed loop system for flying capacitor multilevel inverter with standalone photovoltaic input. International Conference on Power, Energy and Control (ICPEC), 281-286. https://doi.org/10.1109/ICPEC.2013.6527666

[19] Çöteli, R., Açıkgöz, H., Dandil, B., \& Tuncer, S. (2018). Real-time implementation of three-level inverter-based DSTATCOM using neuro-fuzzy controller. Turk. J. of Elec. Eng. \& Comp. Sci., 26, 2088-2103. https://doi.org/10.3906/elk-1708-281

[20] Cobreces, S., Bueno, E. J., Rodriguez, F. J., Salaet, J., \& Bordonau, J. (2006). A new neutral-point voltage control for single-phase three-level npc converters. IEEE Power Electronics Specialists Conference, 1-6, 18 -22.

[21] Rashid, M. H. (2001). Power Electronics Handbook. Academic Press., New York.

[22] Mondal, S. K., Bose, B. K., Oleschuk, V., \& Pinto, J. O. P. (2003). Space vector pulse width modulation of three-level inverter extending operation into overmodulation region. IEEE Trans. on Power Electronics, 18, 604 - 611. https://doi.org/10.1109/TPEL.2003.809342

[23] Zhaoyong, Z., Tiecai, L., Takahashi, T., \& Ho, E. (2004). Design of a universal space vector pwm controller based on FPGA. APEC Nineteenth Annual Conference of IEEE, 16981702.

[24] Ahn, B. S., Cho, S. S., \& Kim, C. Y. (2000). The integrated methodology of rough set theory and artificial neural network for business failure prediction. Expert System with Applications, 18(2), 65-74. https://doi.org/10.1016/S0957-4174(99)00053-6

[25] Jikai, L. \& Yongsheng, M. (2016). A survey of manufacturing oriented topology optimization methods. Advances in Engineering Software, 100, 161-175. https://doi.org/10.1016/j.advengsoft.2016.07.017

[26] Kaveh, A. \& Alinejad, B. (2015). Hypergraph products for structural mechanics. Advances in Engineering Software, 80, 72-81. https://doi.org/10.1016/j.advengsoft.2014.09.017

[27] Lee, Y. H., Suh, B. S., Choi, C. H., \& Hyun D. S. (1999). A new neutral point current control for a 3-level converter/inverter pair system. IEEE Trans. on Industrial Electronics, 3, 1528-1534.

[28] Gurunathan, R. \& Bhat, A. K. S. (2007). Zero-Voltage switching dc link single-phase pulse width-modulated voltage source inverter. IEEE Trans. on Power Electronic, 22(5), 1610-1618. https://doi.org/10.1109/TPEL.2007.904169

[29] Saribulut, L., Teke, A., \& Tumay, M. (2012). Vector-based reference location estimating for space vector modulation technique. Electric Power Systems Research, 51-60. https://doi.org/10.1016/j.epsr.2011.12.004

[30] Wu (2006). High-Power Converters and AC Drives. IEEE Press, Hoboken, New Jersey. https://doi.org/10.1002/0471773719

[31] Acikgoz, H., Kececioglu, O. F., Gani, A., \& Sekkeli, M. (2017). Robust Control of Shunt Active Power Filter Using Interval Type-2 Fuzzy Logic Controller for Power Quality Improvement. Tehnički vjesnik, 24(2), 363-368. https://doi.org/10.17559/TV-20161213004749

[32] Acikgoz, H., Coteli, R., Ustundag, M., \& Dandil, B. (2018). Robust Control of Current Controlled PWM Rectifiers Using Type-2 Fuzzy Neural Networks for Unity Power Factor Operation. Journal of Electrical Engineering \& Technology, 13(2), 822-828.

\section{Contact information}

Ayse Kocalmis BILHAN, Assistant Prof. Dr.

(Corresponding author)

Nevsehir Haci Bektas Veli University,

Faculty of Engineering and Architecture,

Department of Electrical and Electronics Engineering,

2000 Evler Mah. Zübeyde Hanım Cad. 50300/Nevşehir, Turkey

E-mail: akbilhan@gmail.com

Sedat SUNTER, Prof. Dr.

Department of Electrical and Electronics Engineering,

Faculty of Engineering, Ankara University

Gölbaşı Yerleşkesi/Ankara, Turkey

E-mail: ssunter@firat.edu.tr 